\title{
Pharmacological Advances in Opioid Therapy: A Review of the Role of Oliceridine in Pain Management
}

\author{
Alan D. Kaye · Amber N. Edinoff · Katherine C. Babin • \\ Chance M. Hebert · Justin L. Hardin · Elyse M. Cornett • \\ Aaron J. Kaye · Adam M. Kaye · Richard D. Urman
}

Received: June 11, 2021 / Accepted: August 23, 2021 / Published online: September 4, 2021

(C) The Author(s) 2021

\section{ABSTRACT}

Problems with the treatment of acute pain may arise when a patient is opioid-tolerant, such as those on chronic therapy with opioids or opiate replacement therapy, those who misuse opioids, and those who are in recovery. While some of the adverse effects of opioid

A. D. Kaye - E. M. Cornett

Department of Anesthesiology, Louisiana State University Health Shreveport, Shreveport, LA, USA

\section{A. N. Edinoff $(\bowtie)$}

Department of Psychiatry and Behavioral Medicine, Louisiana State University Health Science Center Shreveport, 1501 Kings Hwy, Shreveport, LA 71103, USA

e-mail: aedino@lsuhsc.edu

K. C. Babin - C. M. Hebert · J. L. Hardin School of Medicine, Louisiana State University Health Shreveport, Shreveport, LA, USA

\section{A. J. Kaye}

Department of Anesthesiology and Perioperative Medicine, Medical University of South Carolina, Charleston, SC, USA

\section{A. M. Kaye}

Thomas J. Long School of Pharmacy and Health Sciences, Department of Pharmacy Practice, University of the Pacific, Stockton, CA, USA

\section{R. D. Urman}

Department of Anesthesiology, Perioperative and Pain Medicine, Brigham and Women's Hospital, Harvard Medical School, Boston, MA, USA medications are well known, it is also important to recognize the roles of tolerance and hyperalgesia. Oliceridine can target and modulate a novel $\mu$-receptor pathway. The $G$ protein-biased agonism of oliceridine allows for effective resensitization and desensitization of the muopioid receptor, which decreases the formation of opioid tolerance in patients. Oliceridine has been demonstrated to be an effective and relatively safe intravenous analgesic for the treatment of postoperative pain and is generally well tolerated with a favorable side effect profile when compared to morphine. As the prevalence of pain increases, it is becoming increasingly important to find safe and effective analgesics.

Keywords: Opioids; Oliceridine; Chronic pain; Opioid tolerance 


\section{Key Summary Points}

When a patient is opioid-tolerant, such as those on chronic opioid therapy or opiate replacement therapy, those who misuse opioids, or those in recovery, complications with acute pain treatment may occur.

Oliceridine's $\mathrm{G}$ protein-biased agonism enables effective re-sensitization and desensitization of the mu-opioid receptor, preventing patients from developing opioid tolerance. Oliceridine is an effective and relatively safe intravenous analgesic for the treatment of postoperative pain.

It is generally well tolerated and has a less severe side effect profile than morphine. As pain becomes more prevalent, the development of safe and effective analgesics is critical.

\section{INTRODUCTION}

Pain is universal, and in its acute form serves as a physiological response and protective mechanism to alert the body to current or foreseen tissue damage $[1,2]$. Nociceptors, a type of peripheral neuron, play a crucial role in sensing pain in the form of high temperatures, pressure, and chemical irritants. Nociceptors also facilitate the transmission to higher orders of the nervous system, including the brainstem and cortex, for interpretation [3, 4]. While acute pain often progressively resolves with tissue healing, some acute pain may become chronic pain through a process called "pain chronification" [5]. While the mechanism is not completely understood, chronic pain is becoming increasingly prevalent. It is estimated that in the United States alone, over 100 million adults are affected at any given time by chronic pain, with a healthcare cost of approximately $\$ 560-635$ billion per year [6]. With the growing pervasiveness of chronic pain came a search for effective pharmacological products to treat pain. Opioids have been at the forefront of this discussion.

In the 1990s, the American Pain Society developed and published guidelines for acute and chronic pain management in terms of pharmacological approaches, with funding from Purdue Pharma [7]. Purdue Pharma manufactured Percodan (oxycodone and aspirin) and, later on, the longer-acting opioid, oxycodone [8]. With these guidelines, the 1990s saw a massive rise in opioid prescriptions for pain conditions. When oxycodone was approved by the Food and Drug Administration (FDA), it was marketed as suggesting that addiction to the substance would be "rare," based on a few small clinical trials. [9, 10]. In the early 2000s, the American Pain Society's campaign continued to raise awareness among physicians about assessing and managing pain by publishing "Pain, the Fifth Vital Sign," which was regarded as having excellent credibility [11]. This continued to encourage the liberal use of opioids and initiated patient satisfaction scores as a proxy for healthcare experiences. Medicare then used these scores for disbursements, which put pressure on physicians to continue prescribing the medication to ensure patient satisfaction, which would boost their compensation [12].

This information has additionally created a search for effective pharmacological and nonpharmacological treatments of pain. While opioids are a proven and effective method of successful pain control, particularly in patients with intractable cancer pain, the value of continued research on more effective strategies has become clear in the field of medicine. Oliceridine, the subject of this paper, is an opioid agonist indicated in adults for the management of acute pain severe enough to require an intravenous opioid analgesic.

This article is based on previously conducted studies and does not contain any new studies with human participants or animals performed by any of the authors. 


\section{CURRENT TREATMENT WITH OPIOIDS}

\section{Pharmacogenetics of Opioids}

Modern medicine looks to opioid analgesics as the gold standard treatment for nociceptive pain, which commonly originates from cancer therapy or surgical procedures. The endogenous OPRM1 gene, located on chromosome 6, synthesizes $\mu$ receptors which bind to opioid analgesics and allow for their effects to transpire. Excretion of opioid analgesics is carried out via polymorphic genes that code for phase I and phase II hepatic enzymes. The metabolites can also be excreted by the kidneys. Pharmacokinetic studies have shown that due to the polymorphic characteristics observed in hepatic metabolism of drugs, individuals with different polymorphisms have different exposure and/or metabolism of opioid analgesics [13-16]. Some studies also show that polymorphism affected the pharmacodynamics of individuals. In turn, the outcome of nociceptive pain care varied from patient to patient. Currently, for the use of tramadol and codeine, there are guidelines and recommendations for physicians to appropriately individualize pain treatment for patients. Of all opioids, these two are the only ones that are restricted by these guidelines. However, there are no such recommendations for other opioids, so more research in this field is warranted [17].

\section{Treatment of Acute Pain}

Once the clinician has identified the underlying cause of a patient's pain, they formulate a disease-specific treatment plan. For mild to moderate pain, the suggested pharmacological therapy is a nonsteroidal anti-inflammatory drug (NSAID) or acetaminophen. Patient-specific risk factors guide physicians to prescribe one or the other of these two drugs [18]. Undertreated mental illness is a risk factor for substance abuse [19]. A full review of attentiondeficit/hyperactivity disorder (ADHD), addiction history, depression, post-traumatic stress disorder (PTSD), anxiety, sexual abuse, and a family history of addiction should be evaluated before prescribing an opioid. Problems with the treatment of acute pain arise when the patient is opioid-tolerant, such as those on chronic therapy with opioids or opiate replacement therapy, those who misuse opioids, and those who are in recovery. General practitioners, as well as anesthesiologists and surgeons, must obtain a detailed history of these patients before prescribing opioid analgesics. Importantly, the specific opioids abused by the patient and the last dose taken must be known to avoid the onset of withdrawal. For this reason, multimodal anesthetics and analgesics are used in combination when treating these patients to achieve the most satisfactory treatment and recovery [20].

It must be taken into consideration that not every patient will be truthful about their opioid use. To address this, clinicians have been educated about state prescription drug monitoring programs and other screening tools that can be used to identify current and potential opioid abuse [21]. After surgery, most patients will experience procedural pain and require some anesthetic or analgesic for relief. However, inappropriate treatment plans and prescription of unnecessary opioids lead to the transformation of acute surgical pain into chronic surgical pain or substance abuse disorders.

\section{Treatment of Chronic Pain}

A multicenter, phase IV trial was conducted to determine the variability in response to opioid treatment for chronic cancer pain. Five hundred twenty patients who reported having moderate to severe pain and required opioids to subdue the pain were selected for the study. These patients were placed in groups receiving oral morphine, oxycodone, transdermal fentanyl or buprenorphine for 28 days. Results showed that the average pain intensity (API) decreased with the use of all drugs. However, each group did require adjustments to their treatment plan, including increased daily dosage of opioids, with fentanyl showing the highest increase of $121.2 \%$. Also, each drug group required adjuvant analgesics to decrease the API [22]. 


\section{Misconceptions and Risks of Opioids}

There is continuing controversy concerning the efficacy and safety of opioids. For example, hydromorphone (HM) is a potent opioid commonly used in the emergency department (ED). $\mathrm{HM}$ is a short-acting opioid, a metabolite of hydrocodone with poor bioavailability and a very short half-life. HM displays typical opioid pharmacodynamics by binding to the endogenous $\mu$ receptors that elicit the analgesic and euphoric effect [23]. Compared to morphine, another commonly used opioid analgesic, HM has similar efficacy and safety [24]. However, with the exponentially increased use of HM in the ED nationwide, there has also been an increase in HM abuse and misuse. With this evidence, it is recommended that physicians seek out non-opioid analgesics to treat pain in order to fight the growing incidence of opioid abuse [23]. A systematic review was recently conducted to determine the potential harms and benefits that both physicians and patients should be aware of when prescribing opioids for lower back pain (LBP). From the studies included, it was determined that groups prescribed oral opioids for subacute or chronic pain had higher harm rates and lower pain improvement than those who received non-opioid agents [25].

\section{OLICERIDINE}

One of the significant downfalls of opioids prescribed for pain management is the multitude of associated adverse effects. It was recently discovered that a next-generation intravenous opioid, oliceridine, can reduce or eliminate many of the adverse effects of opioid treatment while providing the analgesic benefits [26]. Oliceridine was fast-tracked in December 2015 and approved by the FDA in August 2020 for use in moderate to severe pain that requires management via opioids [27]. Indications for using oliceridine would be only if the first-line and alternate therapies were not tolerated or did not produce the desired outcome. Some contraindications of oliceridine include a hypersensitivity reaction to the opioid, life- threatening respiratory depression, and paralytic ileus. As with most opioids, it is recommended that the patient be given the lowest effective dose for the shortest duration to maintain patient safety. Treatment with oliceridine should begin with a $1.5 \mathrm{mg}$ dose. The maximum dosage that should be administered within a 24-hour period is $27 \mathrm{mg}$ [26]. Two randomized, double-blind trials, one that was placebo-controlled and the other that was morphine-controlled, aided in establishing the safety and efficacy of oliceridine. Combined, the studies included 790 adult patients who suffered from moderate to severe pain after orthopedic or abdominal surgery. Each trial had some patients in the control, placebo, or morphine group, and the rest were divided into one of three dosing groups of oliceridine. An initial dose of $1.5 \mathrm{mg}$ was given to each experimental group; then the assigned groups either received $0.1 \mathrm{mg}, 0.35 \mathrm{mg}$, or $0.5 \mathrm{mg}$ of oliceridine. The trial results concluded that the patients receiving $0.35 \mathrm{mg}$ and $0.5 \mathrm{mg}$ of oliceridine had significantly lower amounts of pain reported [28]. Oliceridine proved to be as effective and safe as morphine when used as a treatment for nociceptive pain.

\section{Mechanism of Action}

Oliceridine, like many other opioids, relies on the endogenous $\mathrm{mu}[\mu]$ receptors to bind to and elicit an analgesic response to pain caused by activated nociceptors. The $\mu$-opioid receptor belongs to family A, the largest of three families, and is classified as a seven-transmembrane receptor. Much attention has been fixed on specific $G$ protein-biased agonism of the $\mu$-opioid receptor because it does not cause serious adverse effects, unlike the other opioid medications [27]. This particular type of signaling allows for G protein-coupled receptor (GPCR) signaling without activating $\beta$-arrestin-mediated desensitization or signaling, which would negatively regulate the GPCR activity and create life-threatening adverse effects [29]. Oliceridine is the first of its kind with the ability to target and modulate this specific $\mu$-receptor pathway. The $G$ protein-biased agonism of oliceridine 
allows for effective re-sensitization and desensitization of the morphine opioid receptor (MOR), which was shown to decrease the development of opioid tolerance in patients [29]. Since oliceridine is a full opioid agonist, it should be mentioned that it has no maximum analgesic effect, so the dosage must be highly regulated to limit critical central nervous system (CNS) depression [27].

An understanding of ligand binding and allosteric modification on the receptor must be achieved to create oliceridine. Molecular dynamics simulations were done to observe the ligand, TRV130, binding to the activated MOR. The findings from this observation were compared to similar analysis of MOR bound to the morphine ligand. These data should aid in furthering the design and development of improved opioid analgesics [30].

\section{Oliceridine Pharmacokinetics/ Pharmacodynamics}

Since oliceridine is a $G$ protein-biased ligand that binds to MOR coupled to a $\beta$-arrestin inhibitor, the pharmacokinetics and pharmacodynamics will be centered around this process. Oliceridine was seen to competitively bind to the opioid receptor, but with a shorter duration compared to morphine [31]. From the results of an in vitro study, oliceridine was shown to have reputable distribution, with plasma protein binding up to $77 \%$. It has been observed to be metabolized by the hepatic P450 enzymes CYP3A4 and CYP2D6 [26]. It should be highlighted that the administration of oliceridine with CYP2D6 inhibitors or poor metabolizers of CYP2D6 will cause decreased clearance of the opioid, which will increase the patient's exposure to the drug (and therefore the risk of adverse effects). It should be discussed amongst the healthcare providers whether or not the patient should be taken off the CYP2D6 inhibitor or have the dosage of oliceridine lowered. The dosage of oliceridine may need to be increased if the patient being treated takes a CYP3A4 inducer [32]. The pharmacodynamics of oliceridine can affect multiple organ systems within the body, such as the CNS, gastrointestinal tract, and cardiovascular, endocrine, and immune systems. The most commonly noted effect of oliceridine is the depression of respiration by its action on the respiratory centers controlled by the medulla oblongata, which can result in hypoxia if not appropriately regulated. This novel opioid can also cause decreased motility and contractility of the intestines, delaying the digestion of food, which can lead to constipation. Syncope and orthostatic hypotension can result from the vasodilation of peripheral blood vessels.

\section{CLINICAL STUDIES: SAFETY AND EFFICACY}

\section{Oliceridine/TRV130}

A 2014 single-site study evaluated the safety, tolerability, and pharmacological properties of increasing TRV130 doses (0.15-7 mg IV) in healthy subjects, including poor cytochrome P450 2D6 (CYP2D6) metabolism on TRV130, and the tolerability of short infusions. TRV130 showed good tolerance in all dosing groups, with moderate adverse events occurring only in the $7 \mathrm{mg}$ dosing group. Plasma concentrations were highest at the end of the 1-h infusion, declining in multiple phases, indicating more than one distribution compartment. CYP2D6 poor metabolizers had a TRV130 $C_{\max } 1.35$ times higher and clearance that was 50\% lower when compared to their regular metabolizer counterparts. Infusions of $1.5 \mathrm{mg}$ TRV130 for $1,5,15$, and $30 \mathrm{~min}$ were well tolerated [33].

Another study done in 2014 showed that TRV130 had higher peak analgesia that was generally well tolerated with a reduced side effect profile compared to morphine. A singlecenter, double-blind, randomized, placebocontrolled, crossover study evaluated $\mu$-opioid receptor TRV130 agonism against placebo or morphine IV for analgesia, safety, and tolerability in healthy male individuals. The subjects received single doses of TRV130, morphine IV, or placebo on every odd day for 10 days (days 1 , $3,5,7,9)$. TRV130 infusions were associated with a decreased side effect profile up to the $4.5 \mathrm{mg}$ dosage, where the side effects of TRV130 
Table 1 Clinical safety and efficacy

\begin{tabular}{|c|c|c|c|}
\hline $\begin{array}{l}\text { Author } \\
\text { (year) }\end{array}$ & Groups studied and intervention & Results and findings & Conclusions \\
\hline $\begin{array}{l}\text { Viscusi } \\
\text { et al. } \\
(2015) \\
{[35]}\end{array}$ & $\begin{array}{l}\text { Phase } 2 \text {, randomized, double-blind, adaptive- } \\
\text { design study assessing the efficacy and } \\
\text { tolerability of TRV130 in postoperative } \\
\text { bunionectomy patients. The first phase } \\
\text { tested } 1,2,3 \text {, or } 4 \mathrm{mg} \text { IV TRV130 q4h } \\
\text { against placebo IV q4h and } 4 \mathrm{mg} \\
\text { morphine IV q4h. The second phase } \\
\text { tested } 0.5,1,2 \text {, or } 3 \mathrm{mg} \text { q } 3 \mathrm{~h} \text { against } \\
\text { placebo IV q4h and } 4 \mathrm{mg} \text { morphine IV } \\
\text { q4h }\end{array}$ & $\begin{array}{l}\text { In the first phase, } 2 \text { and } 3 \mathrm{mg} \text { TRV130 } \\
\text { showed better NRS TWA0-48 reductions } \\
\text { than placebo, similar to morphine. In the } \\
\text { second phase, TRV130 } 3 \text { mg was more } \\
\text { statistically efficacious than morphine } \\
4 \text { mg. No SAEs occurred in either phase } \\
\text { of the study for TRV130; though some } \\
\text { SEs were found (nausea, dizziness, } \\
\text { headache, and vomiting). TRV130 showed } \\
\text { a smaller effect on oxygen saturation than } \\
\text { morphine did }\end{array}$ & $\begin{array}{l}\text { TRV130 showed statistically significant pain } \\
\text { reduction compared to placebo and } \\
\text { morphine, with no SAEs and decreased } \\
\text { effect on oxygen saturation }\end{array}$ \\
\hline $\begin{array}{l}\text { Soergel } \\
\text { et al. } \\
\qquad(2014) \\
{[33,34]}\end{array}$ & $\begin{array}{l}\text { Single-site study evaluating the safety, } \\
\text { tolerability, and pharmacological } \\
\text { properties of increasing TRV130 doses } \\
(0.15-7 \mathrm{mg} \text { IV) in healthy subjects, the } \\
\text { impact of poor cytochrome P450 2D6 } \\
\text { (CYP2D6) metabolism on TRV130, and } \\
\text { the tolerability of short infusions }\end{array}$ & $\begin{array}{l}\text { TRV130 was well tolerated, with moderate } \\
\text { AEs only in the } 7 \text { mg dosing group. } \\
\text { Plasma concentrations were highest at the } \\
\text { end of the 1-h infusion, declining in } \\
\text { multiple phases, indicating more than one } \\
\text { distribution compartment. CYP2D6 poor } \\
\text { metabolizers had a TRV130 } C_{\max } 1.35 \\
\text { times higher and clearance that } \\
\text { was 50\% lower than normal } \\
\text { metabolizer counterparts. 1-, 5-, 15-, and } \\
\text { 30-min } 1.5 \mathrm{mg} \text { TRV130 infusions were } \\
\text { well tolerated }\end{array}$ & $\begin{array}{l}\text { TRV130 was well tolerated, plasma } \\
\text { concentrations, and relatively low SE } \\
\text { profile. CYP2D6 poor metabolizers had } \\
\text { significantly altered pharmacokinetics and } \\
\text { indicate multiple distribution } \\
\text { compartments }\end{array}$ \\
\hline $\begin{array}{l}\text { Soergel } \\
\text { et al. } \\
\qquad(2014) \\
{[33,34]}\end{array}$ & $\begin{array}{l}\text { Single-center, double-blind, randomized, } \\
\text { placebo-controlled, crossover study that } \\
\text { evaluated } \mu \text {-opioid receptor TRV130 } \\
\text { agonism against placebo or morphine IV } \\
\text { for analgesia, safety, and tolerability in } \\
\text { healthy male individuals. The subjects } \\
\text { received single doses of TRV130, } \\
\text { morphine IV, or placebo on odd days for } \\
10 \text { days }\end{array}$ & $\begin{array}{l}\text { TRV130 infusions were associated with } \\
\text { decreased SE profile up to } 4.5 \mathrm{mg} \text {, where } \\
\text { the SEs of TRV130 were similar to those } \\
\text { associated with morphine IV; while } \\
\text { producing an equivalent analgesic effect. } \\
\text { TRV130 induced a temporary decrease in } \\
\text { respiratory drive that was markedly } \\
\text { decreased from the morphine-induced } \\
\text { respiratory drive that persisted through } \\
4 \mathrm{~h} \text { post-infusion }\end{array}$ & $\begin{array}{l}\text { TRV130 showed higher peak analgesia } \\
\text { compared to morphine, along with } \\
\text { reduced SE profile, and was generally well } \\
\text { tolerated }\end{array}$ \\
\hline $\begin{array}{l}\text { Singla } \\
\text { et al. } \\
(2019) \\
{[36]}\end{array}$ & $\begin{array}{l}\text { A phase } 3 \text {, double-blind, randomized } \\
\text { placebo- and active-controlled study } \\
\text { evaluating the safety and efficacy of } \\
\text { oliceridine in treating abdominoplasty- } \\
\text { related pain. The patients in the study } \\
\text { received a loading dose of oliceridine } \\
1.5 \mathrm{mg} \text {, morphine } 4 \mathrm{mg} \text {, or placebo IV, } \\
\text { which was then followed by demand doses } \\
\text { of } 0.1,0.35 \text {, and } 0.5 \mathrm{mg} \text { either self- or } \\
\text { clinician-administered }\end{array}$ & $\begin{array}{l}\text { All treatment groups except for the placebo } \\
\text { group showed a markedly decreased need } \\
\text { for rescue doses during the treatment. The } \\
\text { placebo group showed the highest } \\
\text { occurrence of rescue pain medication use. } \\
\text { Oliceridine-related SAEs were limited to } \\
\text { syncope and lethargy during the study, } \\
\text { while the other observed SAEs during } \\
\text { treatment were thought to be related to } \\
\text { other factors. GI AEs showed a } \\
\text { proportional dose-related relationship } \\
\text { with oliceridine use up to the } 0.5 \text { mg } \\
\text { oliceridine dose, where the incidence of GI } \\
\text { AEs was similar to the morphine group }\end{array}$ & $\begin{array}{l}\text { Oliceridine was shown to be an effective and } \\
\text { relatively safe IV analgesic for the } \\
\text { treatment of postoperative pain related to } \\
\text { abdominoplasty }\end{array}$ \\
\hline
\end{tabular}

$A E$ adverse event, $G I$ gastrointestinal, $N R S$ numeric rating scale, $S A E$ serious adverse event, $S E$ side effect 
were similar to those associated with morphine IV; while producing an equivalent analgesic effect. TRV130 induced a temporary decrease in respiratory drive markedly shorter from the morphine-induced decreased respiratory drive that persisted through 4-h post-infusion [34].

In 2015, TRV130 showed statistically significant pain reduction compared to placebo and morphine in the treatment of postoperative bunionectomy pain. The phase 2 , randomized, double-blind, adaptive-design study assessed the efficacy and tolerability of TRV130 in postoperative bunionectomy patients. The first phase tested $1 \mathrm{mg}, 2 \mathrm{mg}, 3 \mathrm{mg}$, or $4 \mathrm{mg}$ IV TRV130 every 4 hours (q4h) against placebo IV $\mathrm{q} 4 \mathrm{~h}$ and $4 \mathrm{mg}$ morphine IV $\mathrm{q} 4 \mathrm{~h}$. The second phase tested $0.5 \mathrm{mg}, 1 \mathrm{mg}, 2 \mathrm{mg}$, or $3 \mathrm{mg}$ every 3 hours (q3h) against placebo IV q4h and $4 \mathrm{mg}$ morphine IV q4h. In the first phase, $2 \mathrm{mg}$ and $3 \mathrm{mg}$ TRV130 showed better numeric rating scale (NRS) scores of pain intensity reductions over 48 hours (NRS TWA0-48) than placebo, similar to morphine. In the second phase, TRV130 $3 \mathrm{mg}$ was more statistically efficacious than morphine $4 \mathrm{mg}$. No severe adverse events occurred in either phase of the study for TRV130, though some side effects were reported (nausea, dizziness, headache, and vomiting). TRV130 showed a smaller effect on oxygen saturation than morphine did [35] (Table 1).

Oliceridine was shown to be an effective and relatively safe IV analgesic for the treatment of postoperative pain related to abdominoplasty in a 2019 study. This was a phase 3, double-blind, randomized placebo- and active-controlled study evaluating the safety and efficacy of oliceridine in treating abdominoplasty-related pain. The patients in the study received a loading dose of oliceridine $1.5 \mathrm{mg}$, morphine $4 \mathrm{mg}$, or placebo IV, which was then followed by demand doses of $0.1 \mathrm{mg}, 0.35 \mathrm{mg}$, and $0.5 \mathrm{mg}$ administered by either the patient or clinician. Except for the placebo group, all treatment groups showed a markedly decreased need for rescue doses during the treatment course. The placebo group showed the highest occurrence of rescue pain medication use. Oliceridine-related severe adverse events were limited to syncope and lethargy during the study. The other extreme adverse events observed during treatment were related to other factors. Gastrointestinal adverse events showed a proportional dose-related relationship with oliceridine use up to $0.5 \mathrm{mg}$. The incidence of gastrointestinal adverse events was similar to that of the morphine group [36].

\section{CONCLUSION}

Pain is universal and serves a physiological function in its most acute form. While most forms of acute pain resolve with tissue healing, it can also become chronic through the process of pain chronification $[1,2,5]$. The treatment of chronic pain has a remarkable history, altered by drug availability, research, marketing, and even the political climate. Without necessary caution about their potential for abuse and side effect profile, opioids entered the forefront of the chronic pain market. Opioids in their natural, semisynthetic, and synthetic forms all serve a similar purpose of analgesia and have proven to be very effective in their realm of pain relief [37-39]. The search for breakthrough pain relief in patients with chronic pain conditions, most commonly cancer-related, led to considerations of which medications to use and how to administer them. Other concerns, including the various side effect profile and addictive potential of opioids, opened the conversation for medications like oliceridine. As the prevalence of chronic pain increases, it is becoming increasingly important to find safe and effective medications to treat these conditions. Pain is costly in the economic realm and takes a significant toll on patients' quality of life. Thus, a continued goal of medical research involves exploring the effectiveness of opioids in terms of analgesia while simultaneously reducing the side effects and abuse potential.

\section{ACKNOWLEDGEMENTS}

Funding. No funding or sponsorship was received for this review or publication of this article. 
Authorship. All named authors meet the International Committee of Medical Journal Editors (ICMJE) criteria for authorship for this article, take responsibility for the integrity of the work as a whole, and have given their approval for this version to be published.

Authors' Contributions. A.N.E., K.C.B., C.M.H., and J.L.H. were responsible for writing. A.N.E., A.J.K., A.M.K., E.M.C., R.D.U and A.D.K. were responsible for editing. A.D. and R.D.U were responsible for the manuscript design. All authors have read and agreed to the published version of the manuscript.

Disclosures. Dr. Alan Kaye served on the FDA Advisory Board on Anesthetics, Analgesics, and Addiction Medicine, which reviewed the application for oliceridine. Dr. Richard D. Urman has received funding from Medtronic, Merck, and AcelRx. Amber N. Edinoff, Katherine C. Babin, Chance M. Hebert, Justin L. Hardin, Elyse M. Cornett, Aaron J. Kaye and Adam M. Kaye have nothing to disclose.

Compliance with Ethics Guidelines. This article is based on previously conducted studies and does not contain any new studies with human participants or animals performed by any of the authors.

Data Availability. All data mentioned in this manuscript can be found on PubMed.

Open Access. This article is licensed under a Creative Commons Attribution-NonCommercial 4.0 International License, which permits any non-commercial use, sharing, adaptation, distribution and reproduction in any medium or format, as long as you give appropriate credit to the original author(s) and the source, provide a link to the Creative Commons licence, and indicate if changes were made. The images or other third party material in this article are included in the article's Creative Commons licence, unless indicated otherwise in a credit line to the material. If material is not included in the article's Creative Commons licence and your intended use is not permitted by statutory regulation or exceeds the permitted use, you will need to obtain permission directly from the copyright holder. To view a copy of this licence, visit http:// creativecommons.org/licenses/by-nc/4.0/.

\section{REFERENCES}

1. Collier R. A short history of pain management. CMAJ Can Med Assoc J. 2018;190(1):E26-7.

2. Classification of chronic pain. Descriptions of chronic pain syndromes and definitions of pain terms. Prepared by the International Association for the Study of Pain, Subcommittee on TaxonomyPubMed [Internet]. https://portal.lsuhs.edu/https/ pubmed.ncbi.nlm.nih.gov/3461421/. Cited 18 Feb 2021.

3. Mr C, Gj T. Neurobiology of pain [Internet]. Vol. 25, Advances in psychosomatic medicine. Adv Psychosom Med; 2004. https://pubmed.ncbi.nlm.nih. gov/15248368/. Cited 18 Feb 2021.

4. M C, J S, Cj W. Neuropathic pain: a maladaptive response of the nervous system to damage [Internet]. Vol. 32, Annual review of neuroscience. Annu Rev Neurosci; 2009. https://pubmed.ncbi.nlm.nih. gov/19400724/. Cited 18 Feb 2021.

5. Descending pain modulation and chronification of pain - PubMed [Internet]. https://portal.lsuhs.edu/ https/pubmed.ncbi.nlm.nih.gov/24752199/. Cited 18 Feb 2021.

6. Dj G, P R. The economic costs of pain in the United States [Internet]. Vol. 13, The journal of pain. J Pain; 2012. https://pubmed.ncbi.nlm.nih.gov/ 22607834/. Cited 18 Feb 2021.

7. Boyaji S, Pukenas EW, Urman RD. The opioid epidemic and how anesthesiologists can help. Int Anesthesiol Clin. 2020;58(2):28-33.

8. Umansky L. Keith Wailoo. Pain: a political history. Am Hist Rev. 2015;120(5):1920-1.

9. Mr J, O V, J P, Ad K, Js G, Tt S. A Brief History of the Opioid Epidemic and Strategies for Pain Medicine [Internet]. Vol. 7, Pain and therapy. Pain Ther; 2018. https://pubmed.ncbi.nlm.nih.gov/ 29691801/. Cited 18 Feb 2021.

10. Sh R, Rm F, Fx B, F D, B B, Rj R, et al. Around-theclock, controlled-release oxycodone therapy for osteoarthritis-related pain: placebo-controlled trial and long-term evaluation [Internet]. Vol. 160, Archives of internal medicine. Arch Intern Med; 
2000. https://pubmed.ncbi.nlm.nih.gov/ 10737286/. Cited 18 Feb 2021.

11. Ra M, F W-C, D O, L M, Sm A, L G. Measuring pain as the 5 th vital sign does not improve quality of pain management [Internet]. Vol. 21, Journal of general internal medicine. J Gen Intern Med; 2006. https://pubmed.ncbi.nlm.nih.gov/16808744/. Cited 18 Feb 2021.

12. Core aspects of satisfaction with pain management: cancer patients' perspectives - PubMed [Internet]. https://portal.lsuhs.edu/https/pubmed.ncbi.nlm. nih.gov/19879107/. Cited 18 Feb 2021.

13. Gabriel RA, Burton BN, Urman RD, Waterman RS. Genomics testing and personalized medicine in the preoperative setting. Anesthesiol Clin. 2018;36(4): 639-52.

14. Saba R, Kaye AD, Urman RD. Pharmacogenomics in pain management. Anesthesiol Clin. 2017;35(2): 295-304.

15. Kaye AD, Garcia AJ, Hall OM, Jeha GM, Cramer KD, Granier AL, et al. Update on the pharmacogenomics of pain management. Pharmacogenomics Pers Med. 2019;12:125-43.

16. Cornett EM, Carroll Turpin MA, Pinner A, Thakur P, Sekaran TSG, Siddaiah H, et al. Pharmacogenomics of pain management: the impact of specific biological polymorphisms on drugs and metabolism. Curr Oncol Rep. 2020;22(2):18.

17. Owusu Obeng A, Hamadeh I, Smith M. Review of opioid pharmacogenetics and considerations for pain management. Pharmacotherapy. 2017;37(9): 1105-21.

18. Blondell RD, Azadfard M, Wisniewski AM. Pharmacologic therapy for acute pain. Am Fam Physician. 2013;87(11):766-72.

19. Swendsen J, Conway KP, Degenhardt L, Glantz M, Jin R, Merikangas KR, et al. Mental disorders as risk factors for substance use, abuse and dependence: results from the 10-year follow-up of the National Comorbidity Survey. Addict Abingdon Engl. 2010;105(6):1117-28.

20. Shah S, Kapoor S, Durkin B. Analgesic management of acute pain in the opioid-tolerant patient. Curr Opin Anaesthesiol. 2015;28(4):398-402.

21. Gross JL, Perate AR, Elkassabany NM. Pain management in trauma in the age of the opioid crisis. Anesthesiol Clin. 2019;37(1):79-91.

22. Corli O, Floriani I, Roberto A, Montanari M, Galli F, Greco MT, et al. Are strong opioids equally effective and safe in the treatment of chronic cancer pain? A multicenter randomized phase IV "real life" trial on the variability of response to opioids. Ann Oncol. 2016;27(6):1107-15.

23. Mazer-Amirshahi M, Motov S, Nelson LS. Hydromorphone use for acute pain: Misconceptions, controversies, and risks. J Opioid Manag. 2018;14(1):61-71.

24. Chang AK, Bijur PE, Baccelieri A, Gallagher EJ. Efficacy and safety profile of a single dose of hydromorphone compared with morphine in older adults with acute, severe pain: a prospective, randomized, double-blind clinical trial. Am J Geriatr Pharmacother. 2009;7(1):1-10.

25. Tucker H-R, Scaff K, McCloud T, Carlomagno K, Daly K, Garcia A, et al. Harms and benefits of opioids for management of non-surgical acute and chronic low back pain: a systematic review. Br J Sports Med. 2020;54(11):664.

26. Drugs@FDA: FDA-Approved Drugs [Internet]. https://www.accessdata.fda.gov/scripts/cder/daf/ index.cfm?event=overview.process\&varApplNo= 210730. Cited 1 Feb 2021.

27. OLINVYK (oliceridine) for the Treatment of Acute Pain, USA [Internet]. https://www. clinicaltrialsarena.com/projects/olinvykoliceridine/. Cited 29 Jan 2021.

28. admin. Oliceridine Approved for Management of Acute Pain [Internet]. ASH Clinical News. 2020. https://www.ashclinicalnews.org/onlineexclusives/fda-approves-oliceridine-managementacute-pain/. Cited 29 Jan 2021.

29. Ok HG, Kim SY, Lee SJ, Kim TK, Huh BK, Kim KH. Can oliceridine (TRV130), an ideal novel $\mu$ receptor G protein pathway selective ( $\mu$-GPS) modulator, provide analgesia without opioid-related adverse reactions? Korean J Pain. 2018;31(2):73-9.

30. Schneider S, Provasi D, Filizola M. How oliceridine (TRV-130) binds and stabilizes a $\mu$-opioid receptor conformational state that selectively triggers $g$ protein signaling pathways. Biochemistry. 2016;55(46):6456-66.

31. Altarifi AA, David B, Muchhala KH, Blough BE, Akbarali H, Negus SS. Effects of Acute and repeated treatment with the biased mu opioid receptor agonist trv130 (oliceridine) on measures of antinociception, gastrointestinal function \& abuse liability in rodents. J Psychopharmacol Oxf Engl. 2017;31(6):730-9.

32. Olinvyk (Oliceridine Injection): Uses, dosage, side effects, interactions, warning [Internet]. RxList. https://www.rxlist.com/olinvyk-drug.htm. Cited 29 Jan 2021. 
33. Soergel DG, Subach RA, Sadler B, Connell J, Marion AS, Cowan CL, et al. First clinical experience with TRV130: pharmacokinetics and pharmacodynamics in healthy volunteers. J Clin Pharmacol. 2014;54(3):351-7.

34. Soergel DG, Subach RA, Burnham N, Lark MW, James IE, Sadler BM, et al. Biased agonism of the $\mu$ opioid receptor by TRV130 increases analgesia and reduces on-target adverse effects versus morphine: a randomized, double-blind, placebo-controlled, crossover study in healthy volunteers. Pain. 2014;155(9):1829-35.

35. Viscusi ER, Webster L, Kuss M, Daniels S, Bolognese JA, Zuckerman S, et al. A randomized, phase 2 study investigating TRV130, a biased ligand of the $\mu$-opioid receptor, for the intravenous treatment of acute pain. Pain. 2016;157(1):264-72.

36. Singla NK, Skobieranda F, Soergel DG, Salamea M, Burt DA, Demitrack MA, et al. APOLLO-2: A randomized, placebo and active-controlled phase III study investigating oliceridine (TRV130), a G protein-biased ligand at the $\mu$-opioid receptor, for management of moderate to severe acute pain following abdominoplasty. Pain Pract. 2019;19(7): 715-31.

37. Acevska J, Stefkov G, Petkovska R, Kulevanova S, Dimitrovska A. Chemometric approach for development, optimization, and validation of different chromatographic methods for separation of opium alkaloids. Anal Bioanal Chem. 2012;403(4): 1117-29.

38. Rosenblum A, Marsch LA, Joseph H, Portenoy RK. Opioids and the Treatment of Chronic Pain: Controversies, Current Status, and Future Directions. Exp Clin Psychopharmacol. 2008;16(5):405-16.

39. Valdez CA, Leif RN, Mayer BP. An efficient, optimized synthesis of fentanyl and related analogs. PLoS ONE. 2014;9(9):e108250. 